\title{
NGHIÊN CÚU ĐA DẠNG SINH HỌC DƯƠNG XỈ (POLYPODIOPHYTA) Ở RÙNG LÙN HÒN GIAO TRONG VƯỜN QUỐC GIA BIDOUP NÚI BÀ
}

\author{
Nguyễn Hồng Hạnha ${ }^{a}$, Trần Văn Tiến ${ }^{b^{*}}$
}

aTruờng Trung hoc Phổ thông Trần Phú, Lâm Đồng, Việt Nam

${ }^{b}$ Khoa Sinh học, Trường Đại học Đà Lạt, Lâm Đồng, Việt Nam

\section{Lịch sử bài báo}

Nhận ngày 12 tháng 08 năm 2016 | Chỉnh sửa ngày 12 tháng 09 năm 2016

Chấp nhận đăng ngày 20 tháng 09 năm 2016

\section{Tóm tắt}

Phân tích định luợng về đa dạng sinh học Duơng xỉ ở rù̀ng lùn Hòn Giao Vuờn Quốc Gia Bidoup Núi Bà là co sở dũ liệu cho các giải pháp bảo tồn và sủ dụng bền vũng nguồn tài nguyên đa dạng sinh học. Cá chi số định lương đa dạng sinh học Dương xỉ được sử dụng để phân tích bao gồm: Đa dạng về thành phần loài, mật độ, tần suất xuất hiẹn, độ phong phú, tỉ lẹ A/F, chỉ số Shannon, chỉ số Simpson và chi số tuoong đồng. Kết quả cho thấy, các chi số đa dạng liên quan đến một số nhân tố quan trọng nhu: thành phần các bậc taxon, không gian phân bố. Kết quả điều tra ở toàn khu vục đãa thu thập đuợc 25 loài thuộc 22 chi và 4 bộ. Mức độ đa dạng Duơng xỉ tập trung ở đai độ cao tù 1600-1700 m và thấp nhất là ơ độ cao trên 1800 m. Ngoài ra, múc độ đa dạng của Duơng xỉ thuờng tập trung ở nhũng nơ thuờng có độ ẩm cao và điều kiện dinh duỡng tốt.

Từ khóa: Chỉ số đa dạng; Dương xỉ; Điều tra; Rừng lùn.

\section{MỞ ĐẦU}

Dương xỉ là ngành thực vật có mạch, không có hạt, sinh sản bằng bào tử. Trong lịch sử tiến hóa của trái đất, Dương xỉ đã xuất hiện cuối kỉ Đevon, phát triển mạnh và trở thành rừng Quyết cổ đại vào kỉ Cacbon. Tuy nhiên sau đó số lượng Dương xỉ giảm dần và gần như biến mất vào cuối kỷ Creta. Một số ít sống sót phát triển thành Dương xỉ ngày nay (Freckmann, 2000). Hầu hết các loài Dương xỉ ưa bóng, thường mọc nơi có ánh sáng ít, ẩm ướt. Một số loài Dương xỉ mọc ở kẽ đá, các hang động, đầm lầy và vùng đất ngập nước có tính axit. Ở vùng nhiệt đới, phần lớn Dương xỉ sống phụ sinh trên các thân cây hoặc ở ngọn cây (Phạm, 1999; Mehltreter, Walker, \& Sharpe, 2010). Càng lên vĩ độ cao, độ ẩm giảm, số lượng Dương xỉ giảm và rất ít được tìm thấy ở nơi lạnh và khô (Guo, Kato, \& Ricklefs, 2003)

\footnotetext{
*Tác giả liên hệ: Email: tientv@dlu.edu.vn
} 
Trong kiểu rừng kín thường xanh nhiệt đới núi cao ở Vườn Quốc gia BidoupNúi Bà có kiểu phụ rừng lùn chiếm một diện tích hẹp ở trên đỉnh núi Gia Rích, Hòn Giao, có độ cao từ 1600m trở lên (Vườn Quốc gia Bidoup Núi Bà, 2010). Do điều kiện tự nhiên chi phối kiểu phụ rừng này nên có cấu trúc hoàn toàn khác so với các kiểu rừng khác. Do đó, điều chắc chắc rằng khu hệ Dương xỉ ở kiểu rừng này cũng hoàn toàn khác so với các kiểu rừng khác. Việc nghiên cứu đa dạng sinh học Dương xỉ ở rừng lùn Hòn Giao là điều cần thiết với mục tiêu xác định thành phần loài, điều kiện sống, nghiên cứu phân tích định lượng đa dạng Dương xỉ (Polipodiophyta) nhằm góp phần phục vụ công tác nghiên cứu, bảo tồn và phát triển bền vững thực vật của Vườn Quốc gia Bidoup- Núi Bà.

\section{PHƯƠNG PHÁP NGHIÊN CÚU}

\subsection{Xác định địa điểm và tuyến thu mẫu}

Thu mẫu theo 2 tuyến, một tuyến hướng đông và một tuyến hướng đông bắc. Trên các tuyến lập các ô tiêu chuẩn (OTC) ở ba đai độ cao: 1600m - 1700m, 1700 $1800 \mathrm{~m}$, trên $1800 \mathrm{~m}$. Mỗi OTC có diện tích $2 \mathrm{~m}$ x $2 \mathrm{~m}$, khoảng cách giữa các OTC là 10m. Mỗi đai cao lập 24 OTC.

\section{2. Điều tra thành phần loài}

Định danh các loài Dương xỉ theo Phạm (1999).

\section{3. Đa dạng về các bậc phân loại}

Thống kê số loài, chi, họ và bộ trong ngành Dương xỉ (Polypodiophita) và tỷ lệ \% của các bậc phân loại để từ đó thấy được mức độ đa dạng của chúng.

\subsection{Xác định các chỉ số đa dạng sinh học}

\subsubsection{Mật độ}

Mật độ được tính theo Rastogi (1999); và Sharma (2003). 


\subsubsection{Tần suất}

Tần suất xuất hiện tính theo Rastogi (1999); và Sharma (2003).

\subsection{3. Độ phong phú}

Độ phong phú được tính theo Curtis và Mclntosh (1950)

\subsubsection{Tỷ lệ $A / F$}

Tỷ lệ $\mathrm{A} / \mathrm{F}$ giữa độ phong phú (abundance) và tần suất (frequency) của mỗi loài được sử dụng để xác định các dạng phân bố không gian của loài đó trong quần xã thực vật nghiên cứu. Loài có dạng phân bố liên tục (regular pattern) nếu $\mathrm{A} / \mathrm{F}$ nhỏ hơn $<0,025$, thường gặp ở những hiện trường mà trong đó sự cạnh tranh giữa các loài xảy ra gay gắt. Loài có dạng phân bố ngẫu nhiên nếu $\mathrm{A} / \mathrm{F}$ trong khoảng từ $0,025-0,05$, thường gặp ở những hiện trường chịu các tác động của điều kiện môi trường sống không ổn định. Loài có giá trị $\mathrm{A} / \mathrm{F}>0,05$ thì có dạng phân bố Contagious. Dạng phân bố này phổ biến nhất trong tự nhiên và nó thường gặp ở những hiện trường ổn định (Odum, 1971; Verma, 2000).

\subsubsection{Các chỉ số đa dạng sinh học}

Chỉ số đa dạng sinh học loài (H) được tính theo Shannon và Wiener (1963); Chỉ số mức độ chiếm ưu thế (Cd) được tính theo Simpson (1949); Chỉ số tương đồng (Index of similarity hay Sorensen's Index- SI) được tính theo Shannon và Wiener (1963).

\section{KẾT QUẢ NGHIÊN CỨU}

\section{1. Đa dạng về thành phần các bậc phân loại}

Qua quá trình điều tra, thu mẫu, phân loại Dương xỉ tại khu vực nghiên cứu, bước đầu chúng tôi đã xác định được 25 loài thuộc 4 bộ, 12 họ, 22 chi. Sự đa dạng về thành phần các bậc phân loại của Dương xỉ tại khu vực nghiên cứu được thể hiện ở Bảng 1.

Kết quả Bảng 1 cho thấy Polypodiales có tỷ lệ đa dạng về họ, chi và loài nhất, với 8 họ (66,7\%), 16 chi (72,8\%) và 19 loài (76\%). Tiếp đến là Gleicheniales với 2 họ 
$(16,7 \%), 2$ chi $(9,1 \%)$ và 2 loài $(8 \%)$. Hymenophyllales có 1 họ $(8,3 \%), 3$ chi $(13,6 \%)$ và 3 loài (12\%). Bộ có ít họ, chi và loài nhất là Cyatheales với 1 họ $(8,3 \%), 1$ chi $(4,5 \%)$ và 1 loài $(4 \%)$.

Bảng 1. Đa dạng thành phần các bậc phân loại của Dương xỉ

\begin{tabular}{lcccccc}
\hline \multirow{2}{*}{ Bộ } & \multicolumn{2}{c}{ Họ } & \multicolumn{2}{c}{ Chi } & \multicolumn{2}{c}{ Loài } \\
\cline { 2 - 7 } & SL & TL $(\%)$ & SL & TL $(\%)$ & SL & TL(\%) \\
\hline Cyatheales & 1 & 8,3 & 1 & 4,5 & 1 & 4,0 \\
Gleicheniales & 2 & 16,7 & 2 & 9,1 & 2 & 8,0 \\
Hymenophyllales & 1 & 8,3 & 3 & 13,6 & 3 & 12,0 \\
Polypodiales & 8 & 66,7 & 16 & 72,8 & 19 & 76,0 \\
& 12 & 100 & 22 & 100 & 25 & 100 \\
\hline
\end{tabular}

Ghi chú: SL: Số lượng; TL(\%): Tỷ lệ\%

Trong bộ Polypodiales, họ Polypodiaceae có nhiều loài nhất với 6 loài (31,6\%). Bốn họ có ít loài nhất (1 loài - 5,3\%) bao gồm: Dennstaedtiaceae, Dryopteridaceae, Pteridaceae, Thelypteridaceae.

Chi có nhiều loài nhất là Lindsaea thuộc họ Lindsaeaceae với 3 loài (15,8\%). Kế tiếp là chi Elaphoglossum thuộc họ Lomariopsidaceae với 2 loài (10,5\%). 14 chi còn lại chỉ có 1 loài $(5,3 \%)$ bao gồm: Asplenium và Diplazium thuộc họ Aspleniaceae, Pteridium (Dennstaedtiaceae), Dryopteris (Dryopteridaceae), Sphenomeris (Lindsaeaceae), Lomariopsis (Lomariopsidaceae), Adiantum (Pteridaceae), Coryphopteris (Thelypteridaceae); các chi Calymmodon, Colysis, Crypsinus, Lemmaphyllum, Lepisorus, Scleroglossum đều thuộc họ Polypodiaceae.

\subsection{Mật độ}

Qua kết quả nghiên cứu cho thấy mật độ các loài Dương xỉ tại rừng lùn Hòn Giao khác nhau ở các đai độ cao khác nhau. Kết quả được thể hiện ở Bảng 2.

Ở đai độ cao từ 1600 - 1700m: có 16 loài Dương xỉ được thu thập, trong đó có mật độ cao nhất là Trichomanes digitatum (37760,4 cây/ha); 2 loài có mật độ thấp nhất (104,2 cây/ha) là Colysis semialata và Coryphopteris petelotii. 
Bảng 2. Mật độ Dương xỉ (Polypodiophyta)

\begin{tabular}{|c|c|c|c|}
\hline \multirow{2}{*}{ LOÀI } & \multicolumn{3}{|c|}{ Mật độ (cây/ha) } \\
\hline & $1600-1700 m$ & $1700-1800 m$ & $>1800 \mathrm{~m}$ \\
\hline Cyathea gigantea & 4322,9 & 3125,0 & 2291,6 \\
\hline Drynaria quercifolia & 0,0 & 52,1 & 0,0 \\
\hline Dicranopteris splendida & 1510,4 & 0,0 & 0,0 \\
\hline Mecodium sp. & 729,2 & 1562,5 & 0,0 \\
\hline Trichomanes digitatum & 37760,4 & 60156,2 & 62812,5 \\
\hline Vandenboschia radicans & 0,0 & 52,1 & 156,2 \\
\hline Asplenium nidus & 312,5 & 416,6 & 52,1 \\
\hline Diplazium tomentosum & 416,6 & 52,1 & 0,0 \\
\hline Pteridium aquilinum & 572,9 & 0,0 & 0,0 \\
\hline Dryopteris yaoshanensis & 364,6 & 833,3 & 625,0 \\
\hline Lindsaea bouillodii & 1614,6 & 989,6 & 0,0 \\
\hline Lindsaea chienii & 0,0 & 312,5 & 104,2 \\
\hline Lindsaea dissectiformis & 0,0 & 0,0 & 104,2 \\
\hline Sphenomeris chinensis & 312,5 & 0,0 & 52,1 \\
\hline Elaphoglossum callifolium & 0,0 & 52,1 & 0,0 \\
\hline Elaphoglossum annamense & 729,2 & 0,0 & 0,0 \\
\hline Lomariopsis lineata & 0,0 & 156,2 & 0,0 \\
\hline Calymmodon gracilis & 2395,8 & 6145,8 & 4635,4 \\
\hline Colysis semialata & 104,2 & 104,2 & 156,2 \\
\hline Crypsinus rhynchophyllus & 21822,9 & 14114,6 & 3177,1 \\
\hline Lemmaphyllum carnosum & 0,0 & 52,1 & 0,0 \\
\hline Lepisorus excavatus & 0,0 & 208,3 & 52,1 \\
\hline Scleroglossum pusillum & 0.0 & 833,3 & 781,2 \\
\hline Adiantum soboliferum & 416,6 & 52,1 & 0,0 \\
\hline Coryphopteris petelotii & 104,2 & 312,5 & 1041,6 \\
\hline
\end{tabular}

Ở đai độ cao từ 1700 - 1800m: có 20 loài được thu thập, trong đó Trichomanes digitatum có mật độ cao nhất (60156,2 cây/ha); 6 loài có mật độ thấp nhất (52,1 cây/ha) là Drynaria quercifolia, Vandenboschia radicans, Diplazium tomentosum, Elaphoglossum callifolium, Lemmaphyllum carnosum, Adiantum soboliferum.

Ở độ cao trên 1800m: có 14 loài được thu thập, trong đó Trichomanes digitatum vẫn là loài có mật độ cao nhất (62812,5 cây/ha); 3 loài có mật độ thấp nhất là Asplenium 
nidus, Sphenomeris chinensis, Lepisorus excavatus (52,1 cây/ha).

Như vậy, số loài và số lượng cá thể của mỗi loài khác nhau ở các đai độ cao khác nhau. Sở dĩ có sự có sự khác biệt trên là do ảnh hưởng bởi các nhân tố sinh thái khác nhau như: ánh sáng, nhiệt độ, độ ẩm... (Stein, Gerstner \& Kreft, 2014) và do mỗi loài thích nghi với các điều kiện sinh thái ở những mức độ khác nhau (Bell, Lechowicz \& Waterway, 2000).

\subsection{Tần suất xuất hiện}

Tần suất xuất hiện của các loài Dương xỉ ở các đai độ cao khác nhau là khác nhau. Kết quả thể hiện ở Bảng 3.

Kết quả ở Bảng 3 cho thấy, trong tổng số 25 loài Dương xỉ thu thập được tại khu vực nghiên cứu, loài có tần suất xuất hiện cao nhất là Cyathea gigantea $(68 \%) ; 5$ loài Drynaria quercifolia, Lindsaea dissectiformis, Elaphoglossum callifolium, Lomariopsis lineata, Lemmaphyllum carnosum cùng có tần suất xuất hiện thấp nhất $(0,7 \%)$.

Loài Cyathea gigantea và Trichomanes digitatum có tần suất xuất hiện trên $50 \%$. Điều đó cho thấy, đây loài phân bố rộng, nghĩa là loài có biên độ thích nghi rộng với các nhân tố sinh thái. Loài Calymmodon gracilis và Crypsinus rhynchophyllus có tần suất xuất hiện lớn hơn $25 \%$ và nhỏ hơn $50 \%$, chứng tỏ đây là loài ít gặp. Các loài còn lại đều có tần suất xuất hiện dưới $25 \%$ nên được xếp vào loài ngẫu nhiên (Freckmann, 2000) hay loài có biên độ thích nghi hẹp với các nhân tố sinh thái.

Ở độ cao 1600 - 1700m: Cyathea gigantea có tần suất xuất hiện cao nhất $(81,3 \%)$; 4 loài có tần suất xuất hiện thấp nhất $(4,2 \%)$ là Dicranopteris splendida, Mecodium sp., Colysis semialata, Coryphopteris petelotii.

Ở độ cao 1700 - 1800m: loài có tần suất xuất hiện cao nhất vẫn là Cyathea gigantea $(70,8 \%)$; 9 loài có tần suất xuất hiện thấp nhất $(2,1 \%)$ là Drynaria quercifolia, Vandenboschia radicans, Mecodium sp., Diplazium tomentosum, Elaphoglossum callifolium, Lomariopsis lineata, Colysis semialata, Lemmaphyllum carnosum, Adiantum soboliferum. 
Ở độ cao trên $1800 \mathrm{~m}$ : Trichomanes digitatum có tần suất xuất hiện cao nhất $(77,1 \%)$; 6 loài có tần suất xuất hiện thấp nhất $(2,1 \%)$ là Vandenboschia radicans, Asplenium nidus, Lindsaea chienii, Lindsaea dissectiformis, Sphenomeris chinensis, Lepisorus excavatus.

\section{Bảng 3. Tần suất xuất hiện của các loài Dương xỉ (Polypodiophyta)}

\begin{tabular}{|c|c|c|c|c|}
\hline \multirow{2}{*}{ Loài } & \multicolumn{4}{|c|}{ Tần suất xuất hiện (\%) } \\
\hline & $1600-1700 \mathrm{~m}$ & $1700-1800 \mathrm{~m}$ & $>1800 \mathrm{~m}$ & Tổng thể \\
\hline Cyathea gigantea & 81,3 & 70,8 & 52,1 & 68,0 \\
\hline Drynaria quercifolia & 0,0 & 2,1 & 0,0 & 0,7 \\
\hline Dicranopteris splendida & 4,2 & 0,0 & 0,0 & 1,4 \\
\hline Mecodium sp. & 4,2 & 2,1 & 0,0 & 2,1 \\
\hline Trichomanes digitatum & 43,8 & 66,7 & 77,1 & 62,5 \\
\hline Vandenboschia radicans & 0,0 & 2,1 & 2,1 & 1,4 \\
\hline Asplenium nidus & 12,5 & 10,4 & 2,1 & 8,3 \\
\hline Diplazium tomentosum & 6,3 & 2,1 & 0,0 & 2,7 \\
\hline Pteridium aquilinum & 6,3 & 0,0 & 0,0 & 2,1 \\
\hline Dryopteris yaoshanensis & 8,3 & 8,0 & 10,4 & 11,8 \\
\hline Lindsaea bouillodii & 18,8 & 25,0 & 0,0 & 14,6 \\
\hline Lindsaea chienii & 0,0 & 6,3 & 2,1 & 2,7 \\
\hline Lindsaea dissectiformis & 0,0 & 0,0 & 2,1 & 0,7 \\
\hline Sphenomeris chinensis & 8,3 & 0,0 & 2,1 & 3,5 \\
\hline Elaphoglossum callifolium & 0,0 & 2,1 & 0,0 & 0,7 \\
\hline Elaphoglossum annamense & 12,5 & 0,0 & 0,0 & 4,2 \\
\hline Lomariopsis lineata & 0,0 & 2,1 & 0,0 & 0,7 \\
\hline Calymmodon gracilis & 18,8 & 25,0 & 35,4 & 26,4 \\
\hline Colysis semialata & 4,2 & 2,1 & 4,2 & 3,5 \\
\hline Crypsinus rhynchophyllus & 33,3 & 54,2 & 39,6 & 42,4 \\
\hline Lemmaphyllum carnosum & 0,0 & 2,1 & 0,0 & 0,7 \\
\hline Lepisorus excavatus & 0,0 & 6,3 & 2,1 & 2,7 \\
\hline Scleroglossum pusillum & 0,0 & 12,5 & 6,3 & 6,3 \\
\hline Adiantum soboliferum & 6,3 & 2,1 & 0,0 & 2,7 \\
\hline Coryphopteris petelotii & 4,2 & 8,3 & 25,0 & 12,5 \\
\hline
\end{tabular}

Tần suất xuất hiện của các loài Dương xỉ khác nhau là do biên độ thích ứng của mỗi loài với các nhân tố sinh thái khác nhau (Bell và ctg., 2000). Ngoài ra tần suất xuất 
hiện mỗi loài Dương xỉ cũng khác nhau ở các đai cao khác nhau. Nguyên nhân của hiện tượng này là do điều kiện khí hậu (ánh sáng, nhiệt độ, độ ẩm...), địa hình, thổ nhưỡng ở các đai cao không đồng nhất (Stein và ctg., 2014).

\section{4. Độ phong phú}

Độ phong phú của Dương xỉ cũng khác nhau tùy loài và tùy theo đai cao của khu vực nghiên cứu. Kết quả được thể hiện ở Bảng 4.

Bảng 4. Độ phong phú của các loài Dương xỉ (Polypodiophyta)

\begin{tabular}{|c|c|c|c|c|}
\hline \multirow{2}{*}{ Loài } & \multicolumn{4}{|c|}{ Độ phong phú (cây/m²) } \\
\hline & $1600-1700 \mathrm{~m}$ & $1700-1800 \mathrm{~m}$ & $>1800 \mathrm{~m}$ & Tổng thể \\
\hline Cyathea gigantea & 0,53 & 0,44 & 0,44 & 0,47 \\
\hline Drynaria quercifolia & 0,00 & 0,25 & 0,00 & 0,25 \\
\hline Dicranopteris splendida & 3,62 & 0,00 & 0,00 & 3,62 \\
\hline Mecodium sp. & 1,75 & 7,50 & 0,00 & 3,65 \\
\hline Trichomanes digitatum & 8,63 & 9,02 & 8,10 & 8,57 \\
\hline Vandenboschia radicans & 0,00 & 0,25 & 0,75 & 0,50 \\
\hline Asplenium nidus & 0,25 & 0,40 & 0,25 & 0,31 \\
\hline Diplazium tomentosum & 0,66 & 0,25 & 0,00 & 0,57 \\
\hline Pteridium aquilinum & 0,92 & 0,00 & 0,00 & 0,92 \\
\hline Dryopteris yaoshanensis & 0,44 & 0,50 & 0,60 & 0,51 \\
\hline Lindsaea bouillodii & 0,86 & 0,39 & 0,00 & 0,60 \\
\hline Lindsaea chienii & 0,00 & 0,50 & 0,50 & 0,50 \\
\hline Lindsaea dissectiformis & 0,00 & 0,00 & 0,50 & 0,50 \\
\hline Sphenomeris chinensis & 0,37 & 0,00 & 0,25 & 0,35 \\
\hline Elaphoglossum callifolium & 0,00 & 0,25 & 0,00 & 0,25 \\
\hline Elaphoglossum annamense & 0,58 & 0,00 & 0,00 & 0,58 \\
\hline Lomariopsis lineata & 0,00 & 0,75 & 0,00 & 0,75 \\
\hline Calymmodon gracilis & 1,27 & 2,46 & 1,31 & 1,66 \\
\hline Colysis semialata & 0,25 & 0,50 & 0,37 & 0,35 \\
\hline Crypsinus rhynchophyllus & 6,55 & 2,60 & 0,80 & 3,07 \\
\hline Lemmaphyllum carnosum & 0,00 & 0,25 & 0,00 & 0,25 \\
\hline Lepisorus excavatus & 0,00 & 0,33 & 0,25 & 0,31 \\
\hline Scleroglossum pusillum & 0,00 & 0,66 & 1,25 & 0,86 \\
\hline Adiantum soboliferum & 0,66 & 0,25 & 0,00 & 0,56 \\
\hline Coryphopteris petelotii & 0,25 & 0,37 & 0,42 & 0,38 \\
\hline
\end{tabular}


Kết quả Bảng 4 cho thấy trong số 25 loài Dương xỉ điều tra được khu vực nghiên cứu, loài Trichomanes digitatum có độ phong phú cao nhất $\left(8,57\right.$ cây $\left./ \mathrm{m}^{2}\right) ; 3$ loài là Drynaria quercifolia, Lemmaphyllum carnosum, Elaphoglossum callifolium có độ phong phú thấp nhất $\left(0,25\right.$ cây $\left./ \mathrm{m}^{2}\right)$. Ngoài ra, tùy theo đai độ cao khác nhau mà mỗi loài có độ phong phú khác nhau:

Ở độ cao 1600 - 1700m, loài có độ phong phú cao nhất là Trichomanes digitatum $\left(8,63\right.$ cây $\left./ \mathrm{m}^{2}\right), 3$ loài có độ phong phú thấp nhất là Asplenium nidus, Colysis semialata và Coryphopteris petelotii $(0,25$ cây/m² $)$.

Ở độ cao 1700 - 1800m, loài dương xỉ có độ phong phú cao nhất là Trichomanes digitatum $(9,02$ cây/m² $)$. 6 loài cùng có độ phong phú thấp nhất là Drynaria quercifolia, Vandenboschia radicans, Diplazium tomentosum, Elaphoglossum callifolium, Lemmaphyllum carnosum, Adiantum soboliferum $\left(0,25\right.$ cây $\left./ \mathrm{m}^{2}\right)$.

Ở độ cao trên $1800 \mathrm{~m}$, loài có độ phong phú cao nhất là Trichomanes digitatum $\left(8,1\right.$ cây $\left./ \mathrm{m}^{2}\right), 3$ loài có độ phong phú thấp nhất là Asplenium nidus, Sphenomeris chinensis, Lepisorus excavatus $(0,25$ cây/m²).

Như vậy độ phong phú của Dương xỉ khác nhau tùy theo khả năng thích ứng của chúng với các nhân tố sinh thái tại khu vực nghiên cứu không giống nhau (Bell và ctg., 2000).

\subsection{Tỷ lệ $\mathbf{A} / \mathbf{F}$}

Độ phong phú $(\mathrm{A})$ và tần suất xuất hiện $(\mathrm{F})$ của các loài Dương xỉ ở khu vực nghiên cứu khác nhau dẫn đến tỷ lệ $\mathrm{A} / \mathrm{F}$ và kiểu phân bố của chúng cũng khác nhau. Kết quả được thể hiện ở Bảng 5 .

Kết quả Bảng 5 cho thấy trong tổng số 25 loài Dương xỉ thu thập được tại khu vực nghiên cứu, có 1 loài có tỷ lệ $\mathrm{A} / \mathrm{F}<0,025$ là Cyathea gigantea; 4 loài có tỷ lệ $\mathrm{A} / \mathrm{F}$ trong khoảng 0,025 - 0,05 là Asplenium nidus, Dryopteris yaoshanensis, Lindsaea bouillodii và Coryphopteris petelotii; 20 loài còn lại có tỷ lệ $\mathrm{A} / \mathrm{F}>0,05$. Như vậy, chỉ 
có 1 loài Cyathea gigantea có kiểu phân bố liên tục (4\%); 4 loài Asplenium nidus, Dryopteris yaoshanensis, Lindsaea bouillodii và Coryphopteris petelotii có kiểu phân bố ngẫu nhiên (16\%); 20 loài còn lại có kiểu phân bố Contagious (80\%).

\section{Bảng 5. Tỷ lệ $\mathrm{A} / \mathrm{F}$ và kiểu phân bố của các loài Dương xỉ (Polypodiophyta)}

\begin{tabular}{|c|c|c|c|c|}
\hline \multirow[b]{2}{*}{ Loài } & \multirow[b]{2}{*}{ Tỷ lệ A/F } & \multicolumn{3}{|c|}{ Kiểu phân bố } \\
\hline & & $\begin{array}{c}\text { Liên tục } \\
\text { A/F }<0,025\end{array}$ & $\begin{array}{c}\text { Ngẫu nhiên } \\
0,025 \leq \mathrm{A} / \mathrm{F} \leq 0,05\end{array}$ & $\begin{array}{l}\text { Contagious } \\
\mathrm{A} / \mathrm{F}>0,05\end{array}$ \\
\hline Cyathea gigantea & 0,007 & $\mathrm{x}$ & & \\
\hline Drynaria quercifolia & 0,357 & & & $\mathrm{x}$ \\
\hline Dicranopteris splendida & 2,585 & & & $\mathrm{x}$ \\
\hline Mecodium sp. & 1,738 & & & $\mathrm{x}$ \\
\hline Trichomanes digitatum & 0,137 & & & $\mathrm{x}$ \\
\hline Vandenboschia radicans & 0,357 & & & $\mathrm{x}$ \\
\hline Asplenium nidus & 0,037 & & $\mathrm{x}$ & \\
\hline Diplazium tomentosum & 0,210 & & & $\mathrm{x}$ \\
\hline Pteridium aquilinum & 0,438 & & & $\mathrm{x}$ \\
\hline Dryopteris yaoshanensis & 0,043 & & $\mathrm{x}$ & \\
\hline Lindsaea bouillodii & 0,041 & & $\mathrm{x}$ & \\
\hline Lindsaea chienii & 0,185 & & & $\mathrm{x}$ \\
\hline Lindsaea dissectiformis & 0,714 & & & $\mathrm{x}$ \\
\hline Sphenomeris chinensis & 0,100 & & & $\mathrm{x}$ \\
\hline Elaphoglossum callifolium & 0,357 & & & $\mathrm{x}$ \\
\hline Elaphoglossum annamense & 0,138 & & & $\mathrm{x}$ \\
\hline Lomariopsis lineata & 1,071 & & & $\mathrm{x}$ \\
\hline Calymmodon gracilis & 0,062 & & & $\mathrm{x}$ \\
\hline Colysis semialata & 0,100 & & & $\mathrm{x}$ \\
\hline Crypsinus rhynchophyllus & 0,072 & & & $\mathrm{x}$ \\
\hline Lemmaphyllum carnosum & 0,357 & & & $\mathrm{x}$ \\
\hline Lepisorus excavatus & 0,115 & & & $\mathrm{x}$ \\
\hline Scleroglossum pusillum & 0,136 & & & $\mathrm{x}$ \\
\hline Adiantum soboliferum & 0,207 & & & $\mathrm{x}$ \\
\hline Coryphopteris petelotii & 0,030 & & $\mathrm{x}$ & \\
\hline
\end{tabular}

Kiểu phân bố Contagious phổ biến nhất trong tự nhiên và nó thường gặp ở những hiện trường ổn định (Lê, 2005). Hầu hết các loài Dương xỉ ở rừng lùn Hòn Giao 
có kiểu phân bố Contagious chứng tỏ điều kiện sống ở khu vực nghiên cứu tương đối ổn định, không chịu những tác động hay thay đổi lớn của điều kiện môi trường.

\subsection{Chỉ số đa dạng sinh học loài (H), chỉ số mức độ chiếm ưu thế (Cd)}

Chỉ số đa dạng sinh học loài $(\mathrm{H})$ và chỉ số mức độ chiếm ưu thế $(\mathrm{Cd})$ của các quần xã Dương xỉ không đồng nhất giữa các đai cao khác nhau của khu vực nghiên cứu. Kết quả được trình bày ở Bảng 6 .

\section{Bảng 6. Chỉ số đa dạng sinh học loài (H) và chỉ số mức độ chiếm ưu thế (Cd) của các quần xã Dương xỉ.}

\begin{tabular}{lccc}
\hline & \multicolumn{3}{c}{ Quần xã Dương xỉ theo đai độ cao } \\
\cline { 2 - 4 } Chỉ số ĐDSH & I & II & III \\
& $(1600-1700 \mathrm{~m})$ & $(1700-1800 \mathrm{~m})$ & $(>1800 \mathrm{~m})$ \\
\hline $\mathrm{Cd}$ & 0,357 & 0,482 & 0,689 \\
$\mathrm{H}$ & 2,054 & 1,715 & 1,107 \\
\hline
\end{tabular}

Kết quả Bảng 6 cho thấy chỉ số $\mathrm{H}$ của Quần xã $\mathrm{I}$ lớn nhất $(2,054)$, kế đến là Quần xã II $(1,715)$ và nhỏ nhất là Quần xã III $(1,107)$. Ngược lại chỉ số Cd của Quần xã I nhỏ nhất $(0,357)$, kế đến là Quần xã II $(0,482)$ và cao nhất là Quần xã III $(0,689)$.

Theo Shannon và Weiner (1963), quần xã sinh vật có chỉ số $\mathrm{H}$ càng lớn thì mức độ đa dạng càng thấp. Như vậy mức độ đa dạng sinh học loài của các quần xã Dương xỉ ở rừng lùn Hòn Giao ở các đai độ cao khác nhau là khác nhau. Mức độ đa dạng sinh học giảm dần từ đai thấp tới đai cao.

Chỉ số $\mathrm{Cd}$ được dùng để đánh giá sự đa dạng về số lượng loài của một quần xã thực vật có giá trị và ý nghĩa ngược lại với $\mathrm{H}$, tức là giá trị $\mathrm{Cd}$ càng cao thì tính đa dạng loài càng thấp (Lê, 2005; và Nguyễn, 2013).

Chỉ số $\mathrm{H}$ không chỉ phụ thuộc vào thành phần số lượng loài mà còn phụ thuộc cả số lượng cá thể và xác suất xuất hiện của các cá thể trong mỗi loài (Lê, 2005). Số lượng loài và sự phân bố các cá thể trong từng loài của các quần xã Dương xỉ ở rừng lùn Hòn Giao khác nhau. Quần xã I có 16 loài, 1411 cá thể. Quần xã II có 20 loài, 1720 cá thể. Quần xã 3 III có 14 loài, 1460 cá thể. Như vậy Quần xã III có số lượng loài ít nhất. 
Chính vì vậy Quần xã III có giá trị H thấp nhất.

Quần xã II có nhiều loài hơn Quần xã I nhưng sự phân bố cá thể trong các loài của Quần xã II có sự chênh lệch lớn hơn của Quần xã I. Ví dụ ở Quần xã II, loài Trichomanes digitatum có 1155 cá thể trong khi đó nhiều loài chỉ có 1 cá thể như Vandenboschia radicans, Diplazium tomentosum, Elaphoglossum callifolium, Lemmaphyllum carnosum và Adiantum soboliferum. Còn ở Quần xã I, loài có nhiều cá thể nhất là Trichomanes digitatum (725 cá thể), chỉ có 1 loài có ít cá thể nhất là Colysis semialata (2 cá thể). Do vậy, Quần xã I có giá trị $\mathrm{H}$ cao nhất.

Ngoài ra chỉ số $\mathrm{H}$ còn phụ thuộc vào nhiều yếu tố khác như đặc điểm khí hậu, vĩ độ, độ cao tương đối, mức độ ô nhiễm của môi trường (Huy, 2005). Nguyên nhân quyết định sự biến động đa dạng Dương xỉ theo đai cao là khí hậu, thổ nhưỡng, địa hình. Kết quả nghiên cứu cho thấy ánh sáng, nhiệt độ, pH đất không biểu hiện rõ mối tương quan với sự đa dạng của Dương xỉ. Ngược lại, độ ẩm tương quan rõ với sự đa dạng Dương xỉ (Bhattarai, Vetaas \& Grytnes, 2004). Độ ẩm của rừng lùn Hòn Giao cao (độ ẩm đất trung bình là $80,1 \%$, độ ẩm không khí trung bình là $91,1 \%$ ) do mưa cộng với sương mù xuất hiện nhiều tạo điều kiện cho Dương xỉ phát triển. Ở đai cao 1600 - 1700m, độ ẩm không khí lớn nhất (93,1\%), độ ẩm đất là 80,4\% nên Dương xỉ ở đây đa dạng nhất.

Độ ẩm không khí ở đai cao 1700 - 1800m (89,4\%) nhỏ hơn độ ẩm không khí ở đai cao trên 1800 m $(90,9 \%)$ do ở độ cao trên 1800 m thường xuyên có sương mù. Tuy nhiên độ đa dạng Dương xỉ ở đai cao 1700 -1800m $(1,665)$ lại lớn hơn ở đai cao trên 1800m (1,107). Theo Richard, Bernhardt và Bell (2000), mức độ đa dạng Dương xỉ thường cao hơn ở các khu vực có độ ẩm đất cao và độ phì đất thấp.

Qua kết quả nghiên cứu, độ ẩm đất ở đai cao 1700 - 1800m (80,5\%) lớn hơn ở đai cao trên 1800 m $(79,3 \%)$. Đai cao $1700-1800$ m có độ dốc lớn, mức độ xói mòn mạnh dẫn đến độ phì nhiêu thấp dẫn đến số lượng cá thể của nhiều loài Dương xỉ thấp mặc dù tổng số loài (20 loài) nhiều hơn đai cao trên 1800m (14 loài). Đai cao 1700 $1800 \mathrm{~m}$ có độ ẩm đất cao hơn nhưng độ phì đất lại thấp hơn so với đai cao trên $1800 \mathrm{~m}$. Số lượng loài Dương xỉ ở đai cao 1700 - 1800m lớn hơn nhiều so với ở đai cao trên $1800 \mathrm{~m}$, nên chỉ số đa dạng loài $(\mathrm{H})$ của quần xã Dương xỉ ở đai cao 1700 - 1800m cũng 
lớn hơn ở đai cao trên 1800m.

Kết quả Bảng 6 còn cho thấy chỉ số $\mathrm{H}$ và $\mathrm{Cd}$ biến động giữa các quần xã Dương xỉ ở các đai độ cao khác nhau (H biến động từ $1,107-2,054, \mathrm{Cd}$ biến động từ $0,357-$ 0,689), cấu trúc khu hệ Dương xỉ ở rừng lùn Hòn Giao không đồng nhất. Nguyên nhân là do điều kiện khí hậu (ánh sáng, nhiệt độ, độ ẩm...), thổ nhưỡng giữa các đai cao của khu vực nghiên cứu khác nhau.

\subsection{Chỉ số tương đồng (Sorensen's Index - SI)}

Chỉ số tương đồng giữa các quần xã Dương xỉ ở các đai độ cao khác nhau: giữa Quần xã I (1600 - 1700m) và Quần xã II $(1700-1800 m)$ có chung 12 loài trên tổng số 36 loài; giữa Quần xã I và III (trên 1800m) có chung 9 loài trên tổng số 30 loài; giữa Quần xã II và III có chung 11 loài trên tổng số 34 loài. Chỉ số tương đồng (SI) giữa các quần xã Dương xỉ ở 3 đai cao của khu vực nghiên cứu được thể hiện ở Bảng 7.

\section{Bảng 7. Chỉ số tương đồng - SI của các quần xã Dương xỉ (Polypodiophyta)}

\begin{tabular}{lccc}
\hline Quần xã Dương xỉ & I $(1600-1700 \mathrm{~m})$ & II $(1700-1800 \mathrm{~m})$ & III (> 1800m) \\
\hline I (1600- 1700m) & 1,00 & 0,67 & 0,60 \\
II (1700 -1800m) & & 1,00 & 0,65 \\
III ( > 1800m) & & & 1,00 \\
\hline
\end{tabular}

Kết quả Bảng 7 cho thấy giá trị SI giữa Quần xã I và II là 0,67 , giữa Quần xã I và III là 0,60 , giữa Quần xã II và III là 0,65 . Như vậy, thành phần loài Dương xỉ giữa Quần xã I và II có tính tương đồng cao nhất, kế đến là giữa Quần xã II và III và thấp nhất là giữa Quần xã I và III. Giá trị SI giữa các Quần xã I và II, I và III, II và III khác nhau chứng tỏ mức tương đồng về thành phần loài của các quần xã Dương xỉ ở 3 đai cao khác nhau.Nguyên nhân là do khí hậu, địa hình, thổ nhưỡng giữa các đai cao không đồng nhất (Stein và ctg., 2014).

Theo Lê (2005), đa dạng sinh học beta cho biết sự khác nhau về thành phần loài giữa 2 hiện trường nghiên cứu gần kề dọc theo một lát cắt; chỉ số beta thấp khi thành phần loài của 2 hiện trường nghiên cứu có tính tương đồng cao và ngược lại. Giá trị này đạt tối đa khi giữa 2 hiện trường nghiên cứu không hề có chung một loài xuất hiện 
(tương đồng là zero). Kết quả nghiên cứu cho thấy thành phần loài của các quần xã Dương xỉ ở các đai cao của rừng lùn Hòn Giao có tính tương đồng tương đối cao. Như vậy, mức độ đa dạng sinh học beta trong trường hợp này tương đối thấp.

Tuy nhiên giá trị chỉ số SI giữa Quần xã I và II, II và III, I và III không có sự sai khác lớn $(0,60$ - 0,67) cho thấy có nhiều loài Dương xỉ thích nghi rộng với điều kiện sinh thái của khu vực nghiên cứu nên chúng có mặt ở cả ba đai cao. Kết quả này cũng chứng tỏ mức độ đa dạng sinh học khu hệ Dương xỉ của rừng lùn Hòn Giao có sự khác biệt giữa các đai độ cao khác nhau, tuy nhiên mức độ sai khác không lớn. Có lẽ khu vực nghiên cứu có diện tích chưa đủ lớn để tạo sự khác biệt về các nhân tố sinh thái giữa các đai độ cao.

\section{KẾT LUẬN}

Qua kết quả nghiên cứu Dương xỉ (Polipodiophyta) tại rừng lùn Hòn Giao, Vườn Quốc gia Bidoup-Núi Bà, đi đến một số kết luận sau:

Đa dạng về thành phần các bậc phân loại của Dương xỉ: Khu vực nghiên cứu có 25 loài Dương xỉ thuộc 4 bộ, 12 họ, 22 chi. Polypodiales có nhiều họ, chi và loài nhất, với 8 họ $(66,7 \%), 16$ chi $(72,8 \%)$ và 19 loài $(76 \%)$. Bộ có ít họ, chi và loài nhất là Cyatheales với 1 họ $(8,3 \%), 1$ chi (4,5\%) và 1 loài (4\%).

Đa dạng về dạng sống: Dương xỉ tại khu vực nghiên cứu bao gồm các dạng sống địa sinh và phụ sinh; dạng thân gồm thân gỗ và thân thảo; trạng thái dưới tán rừng lá rộng, ngoài sáng. Ở các đai độ cao khác nhau, thành phần loài và tỷ lệ dạng sống, dạng thân và trạng thái của Dương xỉ khác nhau.

Mật độ: Có 8 loài Dương xỉ có phạm vi phân bố rộng (xuất hiện ở cả ba đai cao), 8 loài Dương xỉ có phạm vi phân bố hẹp (chỉ xuất hiện ở một trong ba đai cao).

Tần suất xuất hiện: Tần suất xuất hiện của Dương xỉ khác nhau tùy loài và tùy theo đai độ cao.

Độ phong phú: Độ phong phú của các loài Dương xỉ ở rừng lùn Hòn Giao khác nhau. Ngoài ra độ phong phú của mỗi loài Dương xỉ khác nhau ở các đai độ cao khác nhau. 
Tỷ lệ A/F: Cyathea giganteacó tỷ lệ $\mathrm{A} / \mathrm{F}<0,025$ nên có kiểu phân bố liên tục(4\%). 4 loài (Asplenium nidus, Dryopteris yaoshanensis, Lindsaea bouillodii, Coryphopteris petelotii) có tỷ lệ $\mathrm{A} / \mathrm{F}$ trong khoảng 0,025 - 0,05 nên có kiểu phân bố ngẫu nhiên(16\%). 20 loài còn lại có tỷ lệ $\mathrm{A} / \mathrm{F}>0,05$ có kiểu phân bố Contagious (80\%).

Chỉ số H của quần xã Dương xỉ ở độ cao 1600 - 1700m lớn nhất $(2,054)$, kế đến là ở độ cao 1700 - 1800m(1,715) và nhỏ nhất là ở độ cao trên $1800 \mathrm{~m}(1,107)$.

Chỉ số Cd của quần xã Dương xỉ ở độ cao 1600 - 1700m nhỏ nhất $(0,357)$, kế đến là ở độ cao 1700 - 1800m $(0,482)$ và cao nhất là ở độ cao trên $1800 \mathrm{~m}(0,689)$.

Mức độ đa dạng sinh học giảm dần từ đai độ cao thấp tới đai độ cao cao.

Quần xã Dương xỉ ở độ cao 1600 - 1700m và 1700 - 1800m có tính tương đồng về thành phần loài cao nhất; kế đến là giữa quần xã Dương xỉ ở độ cao 1700 - $1800 \mathrm{~m}$ và trên $1800 \mathrm{~m}$, thấp nhất là giữa quần xã Dương xỉ ở độ cao 1600 - 1700m và trên $1800 \mathrm{~m}$.

\section{TÀI LIỆU THAM KHẢO}

Bell, G., Lechowicz, M. J., \& Waterway, M. J. (2000). Environmental heterogeneity and species diversity of forest sedges. Journal of Ecology, 88, 67-87.

Bhattarai, K. R., Vetaas, O. R., \& Grytnes, J. A. (2004). Fern species richness along a central Himalayan elevational gradient, Nepal. Journal of Biogeography, 31, $389-400$.

Curtis, J. T., \& McIntosh, R. P. (1950). The interrelations of certain analytic and synthetic phytosociological characters. Ecology, 31, 434-455.

Lê, B. D., \& Lê, T. A. T. (2015). Sinh thái thực vật. Thành phố Hồ Chí Minh, Việt Nam: NXB. Đại học Quốc gia TP. Hồ Chí Minh.

Freckmann, R. W. (2000). The taxonomy of vascular plants. Department of Biology University of Wisconsin Stevens Point.

Guo, Q., Kato, M., \& Ricklefs, R. E. (2003). Life history, diversity and distribution: A study of Japanese pteridophytes. Ecography, 26, 129-138.

Lê, Q. H. (2005). Phương pháp nghiên cứu phân tích định lượng các chỉ số đa dạng sinh học thực vật. Tạp chí Nông nghiệp và Phát triển nông thôn, 3(4), 117-121.

Phạm, H. H. (1999). Cây cỏ Việt Nam (Tập 1). Thành phố Hồ Chí Minh, Việt Nam: NXB Trẻ.

Nguyễn, T. T. (2013). Phân tích một số chỉ số đa dạng sinh học loài cây gỗ của thảm 
thực vật rừng trên núi đá vôi tại Khu bảo tồn thiên nhiên Thần $\mathrm{Sa}$ - Phượng Hoàng, tỉnh Thái Nguyên. Tạp chí Khoa học Lâm Nghiệp, 4, 2961-2967.

Vườn Quốc Gia Bidoup - Núi Bà, tỉnh Lâm Đồng (2015). Hồ sơ đề củ vuoòn di sản Asian.

Mehltreter, K., Walker, L. R., \& Sharpe, J. M. (2010). Fern Ecology. Cambridge, UK: Cambridge University Press.

Odum, P. E. (1971). Fundamentals of ecology. Pennsylavania, USA: Saunders Philadelphia.

Rastogi, A. (1999). Methods in applied Ethnobotany: Lesson from the field. Kathmandu, Nepal: International Center for Integrated Mountain Development (ICIMOD).

Richard, M., Bernhardt, T., \& Bell, G. (2000). Environmental heterogeneity and the spatial structure of fern species diversity in one hectare of old-growth forest. Ecography, 23, 231-245.

Shannon, C. E., \& Wiener, W. (1963). The mathematical theory of communities, Illinois, USA: Urbana University Press.

Sharma, P. D. (2003). Ecology and environment. New Delhi, India: Rastogi Publication.

Simpson, E. H. (1949). Measurment of diversity. Nature, 163, 688-695.

Stein, A., Gerstner, K., \& Kreft, H. (2014), Environmental heterogeneity as a universal driver of species richness across taxa, biomes and spatial scales. Ecology Letters, $17,866-880$.

Verma, R. K. (2000). Analysis of species diversity and soil quality under Tectona grandis L.f. and Acacia catechu (L.f.) Wild plantations raised on degraded bhata land. Indian Journal of Ecology, 27(2), 97-108. 


\title{
STUDYING BIODIVERSITY OF FERN (POLYPODIOPHYTA) IN HON GIAO DWARF FOREST - BIDOUP NUI BA NATIONAL PARK
}

\author{
Nguyen Hong Hanh ${ }^{a}$, Tran Van Tien ${ }^{b^{*}}$ \\ ${ }^{a}$ Tran Phu High School, Lamdong, Vietnam \\ ${ }^{b}$ The Faculty of Biology, Dalat University, Lamdong, Vietnam \\ ${ }^{*}$ Corresponding author: Email: tientv@dlu.edu.vn
}

\begin{abstract}
Article history
Received: August 12 $2^{\text {th }}, 2015$ | Received in revised form: September $12^{\text {th }}, 2016$

Accepted: September $20^{\text {th }}, 2016$
\end{abstract}

\begin{abstract}
The quantitative analysis of Fern diversity for Hon Giao dwarf forest in Bidoup Nui Ba National Park is necessary to create a solution for conservation and sustainable use of biodiversity resources. The quantitative analysis of biology in order to determine the following in indicies: taxon diversity, Density $(D)$, Frequency $(F)$, Abundance $(A), A / F, H$ (Shannon's index), Cd (Simpson'S index), SI (Sorensen's index) was used to quantify the diversity of Fern. The results showed that quantitative support for the generality of positive heterogeneity-richness relationship across heterogeneity components, taxa, spartial scale. The taxon diversity at the study sites were recorded with 25 species, 22 genus and 4 orders of Fern. The species distributed and varied greatly in spatial scale. Fern diversity was the highest at sites with low altitudes (1600-1700 $\mathrm{m}$ a.s.l.) and the lowest at site with high altitudes $(\geq 1800 \mathrm{~m}$ a.s.l.). Otherwise, based on the sites were they grew, Fern diversity was also the higest with high soil moisture, fertility.
\end{abstract}

Keywords: Diversity index; Dwarf forest; Fern; Inventory. 